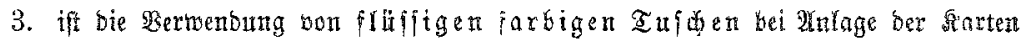
whrte Taditeile geftattet,

4. ber aufgetragene Firnto exfoint waffertyell, we

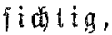

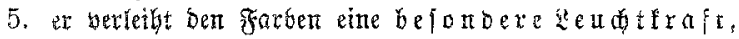

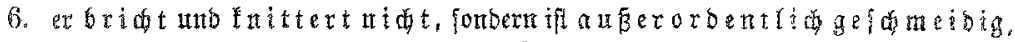

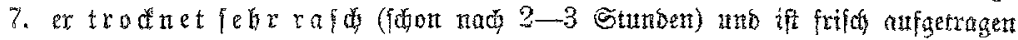

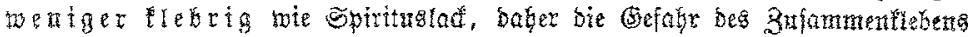

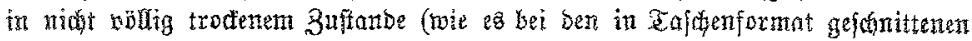
Rorten vorfonnten foun) geringer.

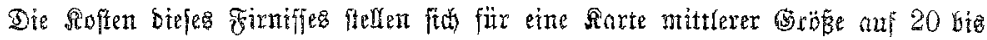

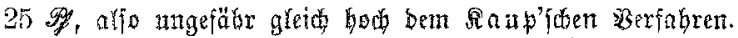

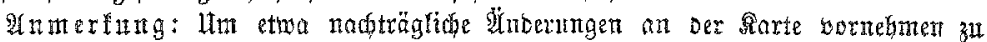

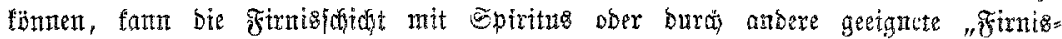

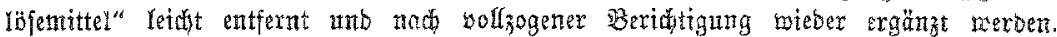

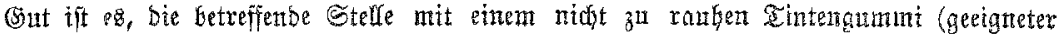

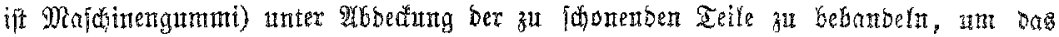

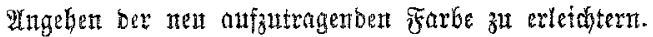

Frificister,

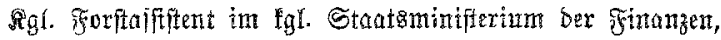
Mintiftertal = gorftobtetlung.

\title{
Pissodes notatus in fichten.
}

Sim Miai 1909 f.rtb in Forftamt Riumberg=

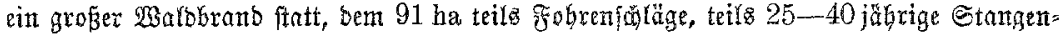
bijlzer zun Spfer fielen. Das burd ben Branb getötete Matertal Dex Yesteren wutrbe auf bem Stod, in soje getetlt, berfteigert, bagegen blieb bas idmadje Material ber

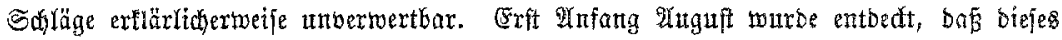

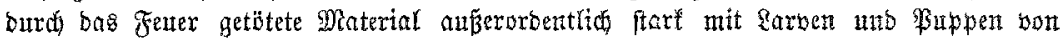

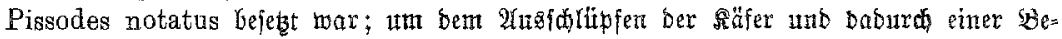

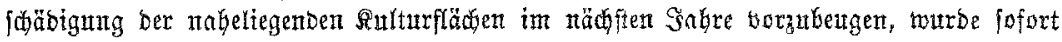

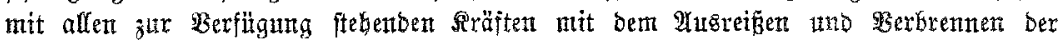
befallenen Bffanzen begontent uno biefe Arbett mit einem Roftenaufwatho bon nabezu

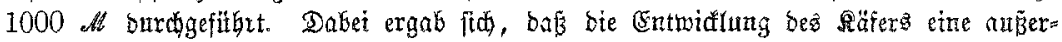

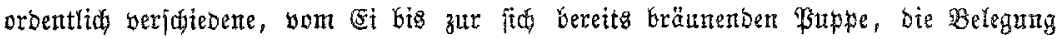
baher zat jebr veriogiebenert Beiten erfolgt war.

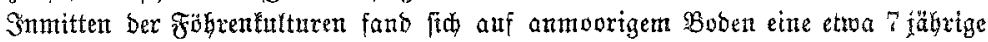

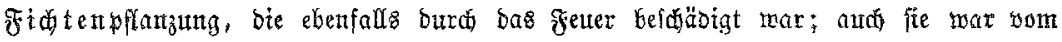

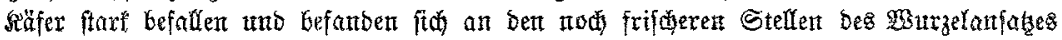

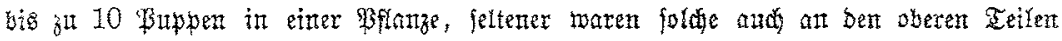
zut fithoen.

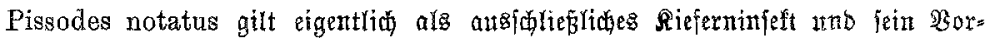

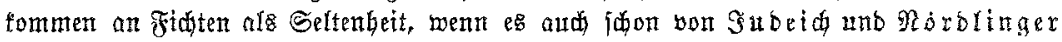

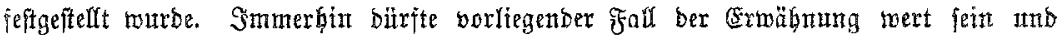
nebenbei auf bie Borfidt aufmerfjam maden, bie aud bei Brandfäden mit amideinents

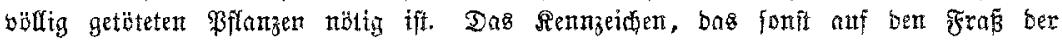
Rarven aufmertian madt, die welferden Triebe, feğlen hier! 